\title{
Long-term Management of a Patient with Apert Syndrome
}

Shinya Horiuchi ${ }^{1}$, Hiroko Sato ${ }^{2}$, Akihiko Iwasa ${ }^{3}$, Aki Ichihara ${ }^{4}$, Hirofumi Tenshin ${ }^{5}$, Keiichiro Watanabe ${ }^{6}$, Masahiro Hiasa ${ }^{7}$, Ichiro Hashimoto ${ }^{8}$, Eiji Tanaka ${ }^{9}$

\begin{abstract}
Aim and objective: To present an Apert syndrome patient with midfacial growth deficiency treated with Le Fort III distraction osteogenesis and subsequent two-jaw surgery.

Background: Apert syndrome is expressed as a severe and irregular craniosynostosis, midfacial hypoplasia, and symmetric syndactyly in the fingers and toes. For craniosynostosis syndromes, treatment planning is complex due to the disharmony between facial profile and occlusion.

Case description: A 4-year-and-5-month-old boy, diagnosed with Apert syndrome, showed a concave profile accompanied with midfacial hypoplasia, moderate exorbitism, a reversed occlusion of $-10.0 \mathrm{~mm}$, an anterior open bite of $-5.0 \mathrm{~mm}$, and skeletal class III jaw-base relationship. The patient, aged 15 years and 4 months, underwent a Le Fort III osteotomy, and subsequent osteodistraction was performed via a rigid external distraction (RED) device. His midfacial bone was advanced by approximately $7.0 \mathrm{~mm}$. One year after the distraction, preoperative treatment with 0.018-in preadjusted edgewise appliances was initiated. Two-jaw surgery with a Le Fort I osteotomy and bilateral sagittal split ramus osteotomy was performed after 42 months of preoperative orthodontic treatment. At the age of 20 years and 9 months, his facial profile dramatically changed to a straight profile, and an acceptable occlusion with an adequate interincisal relationship was obtained. A functional occlusion with an excellent facial profile was maintained throughout the 2-year retention period, although the upper dental arch width was slightly decreased, resulting in the recurrence of the left posterior crossbite.
\end{abstract}

Conclusion: Our report indicates the necessity of long-term follow-up in patients with craniosynostosis because of syndrome-specific growth and methodologically induced relapse.

Clinical significance: The two-stage operation combining early distraction osteogenesis and postgrowth orthognathic surgery proves to be an effective therapy for correcting midfacial hypoplasia and skeletal mandibular protrusion caused by Apert syndrome.

Keywords: Apert syndrome, Craniosynostosis, Distraction osteogenesis, Le Fort III osteotomy, Maxillary growth deficiency.

The Journal of Contemporary Dental Practice (2021): 10.5005/jp-journals-10024-3201

\section{InTRODUCTION}

Apert syndrome, a rare craniosynostosis syndrome, represents approximately $4-5 \%$ of all craniosynostosis syndromes with an estimated incidence of 1 in 65,000-160,000 living babies. ${ }^{1,2}$ Like other craniosynostosis syndromes such as Crouzon, Pfeiffer, Jackson-Weiss, and Beare-Stevenson syndromes, it involves allelic mutations of the fibroblast growth factor receptor 2 (FGFR2) genes located on chromosome 10q25-10q26. 3 .

This disorder is expressed as severe and irregular craniosynostosis, midfacial hypoplasia, and symmetric syndactyly in the fingers and toes. ${ }^{3}$ As for the oral manifestation, Apert syndrome exhibits tooth impaction, severe crowding, irregular and/or delayed tooth eruption, thick gingiva, and congenitally missing teeth. Other frequent phenotypes commonly seen in Apert syndrome include class III malocclusion, anterior open bite, and bilateral or unilateral posterior crossbite. $^{5}$

For craniosynostosis syndromes, treatment planning is complex due to the disharmony between the facial profile and occlusion. A single osteotomy is sometimes inappropriate for improving complicated skeletal discrepancies. Nowadays, distraction osteogenesis for maxillary advancement has been a common surgical technique for patients with skeletal mandibular protrusion caused by severe maxillary growth deficiency. ${ }^{6-9}$ The rigid external distraction (RED) system is comprised of the external distraction devices reported by Polley and Figueroa for the first time. ${ }^{7}$ This approach allows the management of these patients with promising functional and esthetic outcomes. ${ }^{7,9,10}$ Previously, we reported a 9-year follow-up of Le Fort III distraction
1,4,5 Department of Orthodontics and Dentofacial Orthopedics, Tokushima University Hospital, Tokushima, Japan

2,3,6,7 Department of Orthodontics and Dentofacial Orthopedics, Tokushima University Graduate School of Biomedical Sciences, Tokushima, Japan

${ }^{8}$ Department of Plastic and Reconstructive Surgery, Tokushima University Graduate School of Biomedical Sciences, Tokushima, Japan

${ }^{9}$ Department of Orthodontics and Dentofacial Orthopedics, Tokushima University Graduate School of Biomedical Sciences, Tokushima, Japan; Department of Orthodontics, King Abdulaziz University, Jeddah, Saudi Arabia

Corresponding Author: Eiji Tanaka, Department of Orthodontics and Dentofacial Orthopedics, Tokushima University Graduate School of Biomedical Sciences, Tokushima, Japan; Department of Orthodontics, King Abdulaziz University, Jeddah, Saudi Arabia, Phone: +81-88-6337356, e-mail: etanaka@tokushima-u.ac.jp

How to cite this article: Horiuchi S, Sato $H$, Iwasa A, et al. Long-term Management of a Patient with Apert Syndrome. J Contemp Dent Pract 2021;22(10):1184-1190.

Source of support: Nil

Conflict of interest: None

osteogenesis via the RED device in a patient with Crouzon syndrome in which less or minimal relapse was found for long-term retention, implying a long-term stability of midfacial advancement with distraction osteogenesis. ${ }^{11}$ 
The purpose of this article is to present an Apert syndrome patient with midfacial growth deficiency treated with Le Fort III distraction osteogenesis and subsequent two-jaw surgery.

\section{Case Description}

A 4-year-and-5-month-old boy visited the Department of Orthodontics, Tokushima University Hospital, with an introduction from the Department of Plastic Surgery. The patient complained mainly of masticatory disturbances associated with an anterior crossbite. He was prenatally diagnosed with Apert syndrome with a germline mutation of S252W in the FGFR2 gene, and no other family members showed a similar condition. ${ }^{12,13}$ He showed a concave facial profile with severe midfacial hypoplasia, and moderate exorbitism was noted (Fig. 1A). A reversed occlusion of $-10.0 \mathrm{~mm}$ and anterior open bite of $-5.0 \mathrm{~mm}$ were observed, and the terminal plane was mesial step type bilaterally (Fig. 1B). At birth, he had syndactyly of the hands and feet and underwent surgery several times to correct the deformed fingers. ${ }^{14}$

Panoramic radiograph showed that the maxillary lateral incisors were congenitally missing bilaterally (Fig. 1D). Compared with the Japanese norm, ${ }^{15}$ pretreatment cephalometric analysis revealed a skeletal class III jaw-base relationship (A-point-nasion-B-point angle (ANB), $-11.2^{\circ}$ ) involving severe maxillary deficiency (sella-nasion-a-point angle (SNA), 63.0 $0^{\circ}$ ) (Figs 1D and 2, Table 1). The ramus height and gonial angle of the mandible were larger than those of the Japanese control; consequently, the lower anterior facial height was larger than the Japanese male standard, indicating a long-faced syndrome.

\section{Treatment Objectives}

The patient was diagnosed with skeletal mandibular prognathism involving severe midfacial hypoplasia, a skeletal class III relationship, and a high mandibular plane angle tendency. The objectives of the treatment were (1) to improve a concave facial profile, (2) to correct the reversed occlusion and anterior open bite, (3) to accomplish an adequate interincisal relationship, and (4) to achieve an acceptable occlusion with good function. We then attempted to advance the midface with Le Fort III distraction osteogenesis after growth spurt, followed by maxillary and/or mandibular osteotomy after the end of growth.

\section{Treatment Alternatives}

Several surgical procedures have been developed to accomplish a functional and acceptable occlusion with a proper facial profile. Although early orthopedic treatment of a growth-deficient maxilla

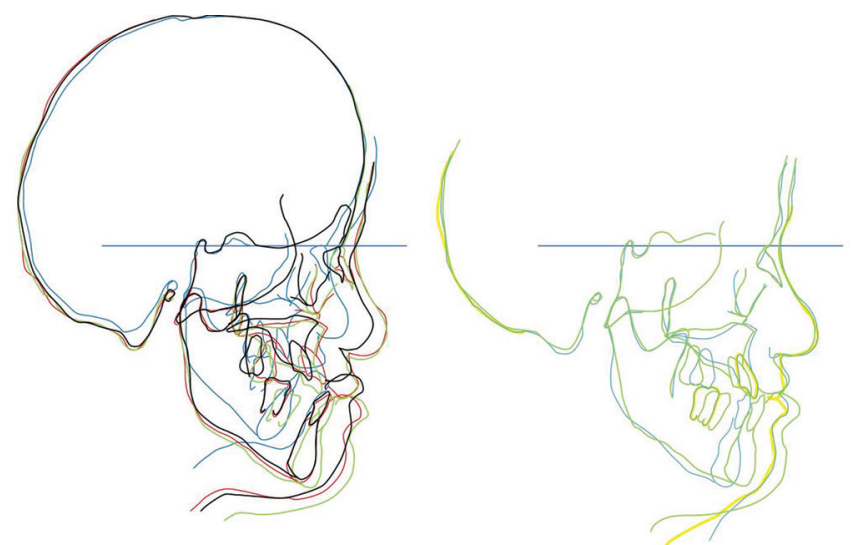

Fig. 2: Superimposition of cephalometric tracings at initial visit (blue line), before maxillary distraction osteogenesis (black line), before multibracket treatment after maxillary distraction osteogenesis (red line), before two-jaw surgery (green line), after treatment (light blue line), and after 2-year retention (yellow line)
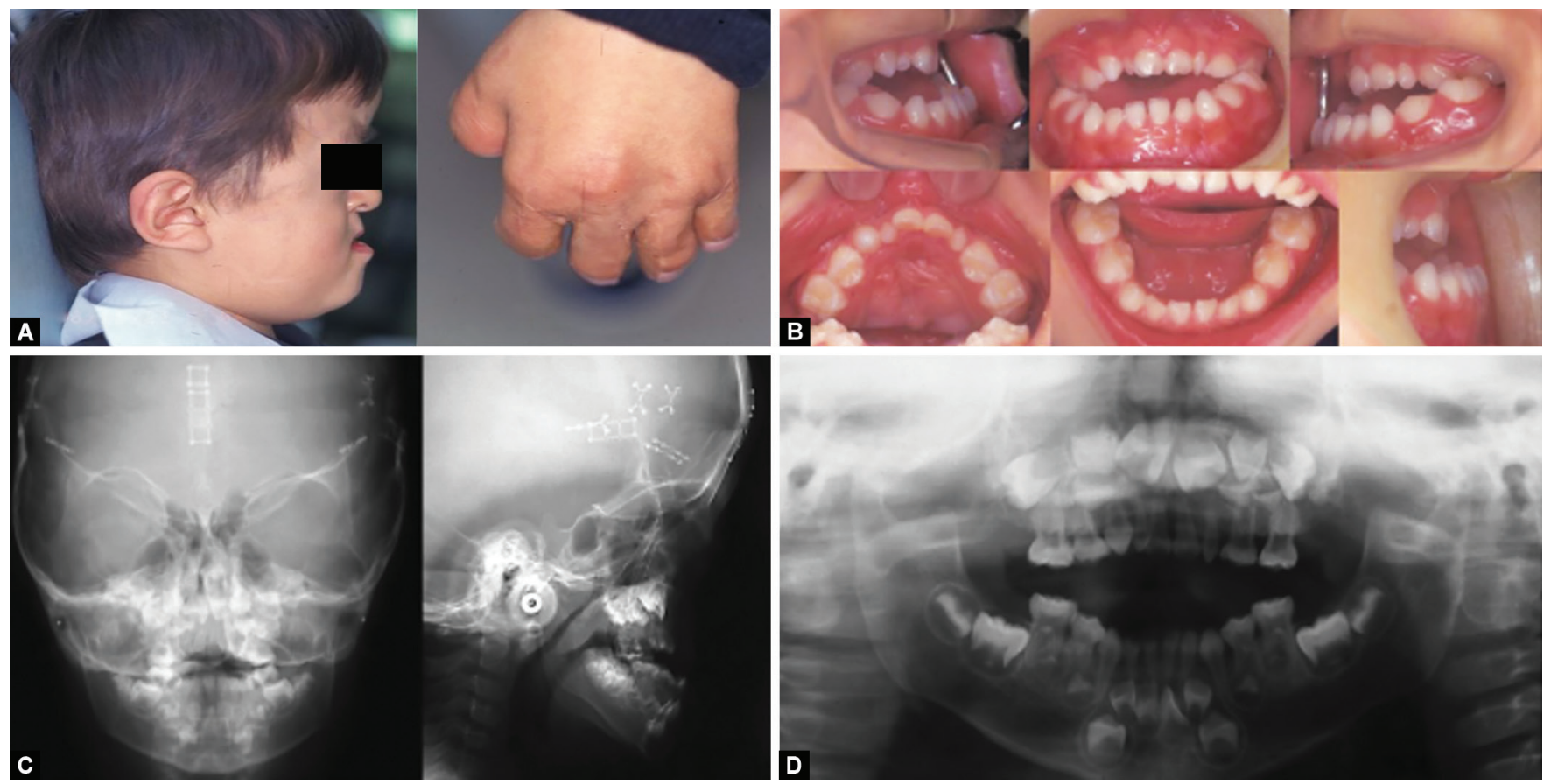

Figs 1 A to D: Pretreatment: (A) Facial and digital photographs; (B) Intraoral photographs; (C) Frontal and lateral cephalograms; (D) Panoramic radiograph 
with reverse-pull headgear and chin cap may be considered an effective remedy to treat skeletal class III without surgical invasion, the nonsurgical procedure could not correct the severe skeletal discrepancy caused by midfacial hypoplasia associated with an Apert syndrome.

In this regard, a surgical orthodontic treatment was applied to improve skeletal discrepancy and obtain informed consent from the patient and his parents. For midfacial advancement, we chose either simple Le Fort III osteotomy or osteodistraction. Although traditional surgical orthodontic treatments may provide a good prognosis in growing patients with craniosynostosis; however, we selected distraction osteogenesis following Le Fort III osteotomy after his growth spurt for the following reasons: (1) the vertical discrepancy was significantly larger even at the initial stage, (2) obstructive sleep apnea and exorbitism were not so severe, and (3) the midfacial advancement was more expected in adolescence than in childhood. For the distraction device, we adopted a RED system because of its several advantages in comparison with the internal device: easy and secure placement of the device, feasibility of the protraction direction control, and no necessity for a second operation to remove the device.

\section{Treatment Progress}

Until the end of his active growth, we followed him with plaque and caries control. The patient, aged 15 years and 4 months, underwent a Le Fort III osteotomy, and the RED II system (KLS Martin, Tuttlingen, Germany) was fixed to the cranial bones simultaneously (Fig. 3). Midfacial advancement was initiated from 5 days after surgery and lasted for 18 days, resulting in approximately $7.0 \mathrm{~mm}$ advancement (Fig. 2). After completion of the midfacial advancement, the external device was kept in place for 4 weeks with rigid retention, and the facemask was worn for a further 7 months while sleeping.

At the age of 16 years and 4 months, 0.018 -in-slot preadjusted edgewise appliances were placed in both the maxillary and mandibular arches, and preoperative treatment was started (Fig. 4). Two-jaw surgery including a Le Fort I osteotomy and bilateral sagittal split ramus osteotomy was performed after 42 months of preoperative orthodontic treatment. At the age of 20 years and 9 months, postoperative treatment was completed and a functional and acceptable occlusion was achieved. Then, all the appliances were removed, and the metal retainer and circumferential retainer were applied to the maxillary and mandibular arches, respectively. The total active treatment period was 66 months.

\section{Treatment Results}

After the Le Fort III distraction osteogenesis, the midfacial hypoplasia was drastically improved although the reverse
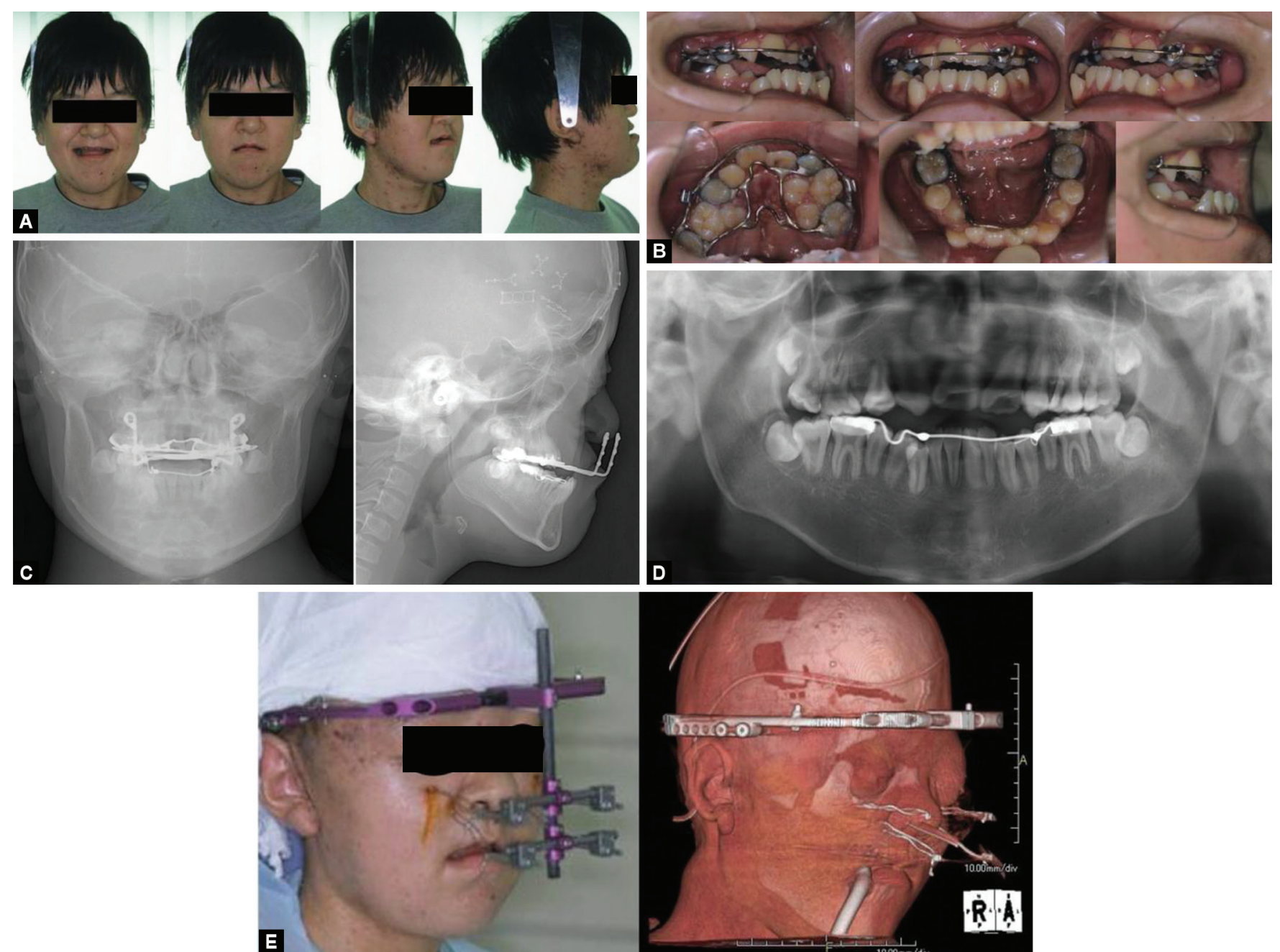

Figs 3A to E: Predistraction: (A) Facial photographs; (B) Intraoral photographs; (C) Frontal and lateral cephalograms; (D) Panoramic radiograph; (E) Facial photograph and three-dimensional computed tomography image during maxillary osteodistraction 


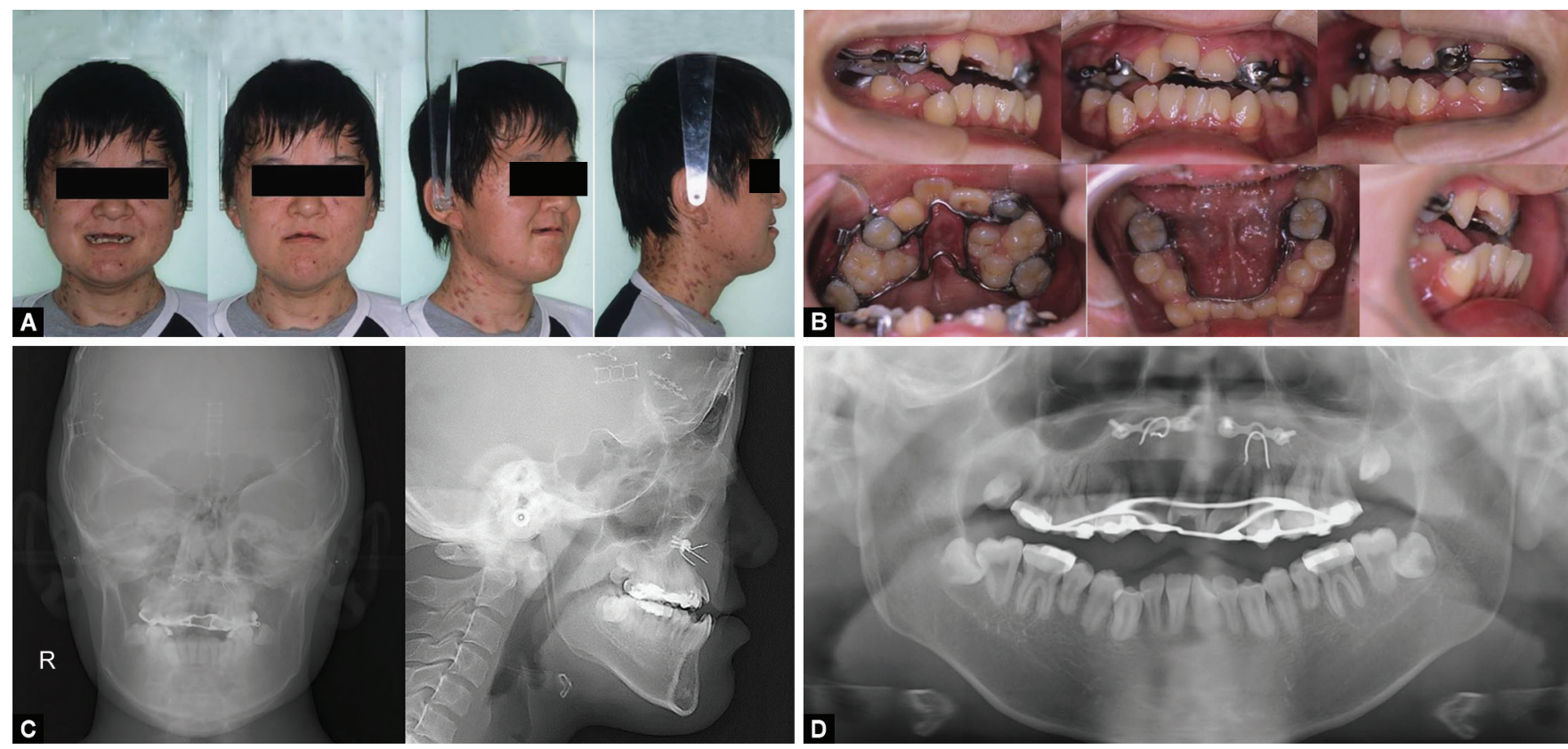

Figs 4A to D: Postdistraction: (A) Facial photographs; (B) Intraoral photographs; (C) Frontal and lateral cephalograms; (D) Panoramic radiograph
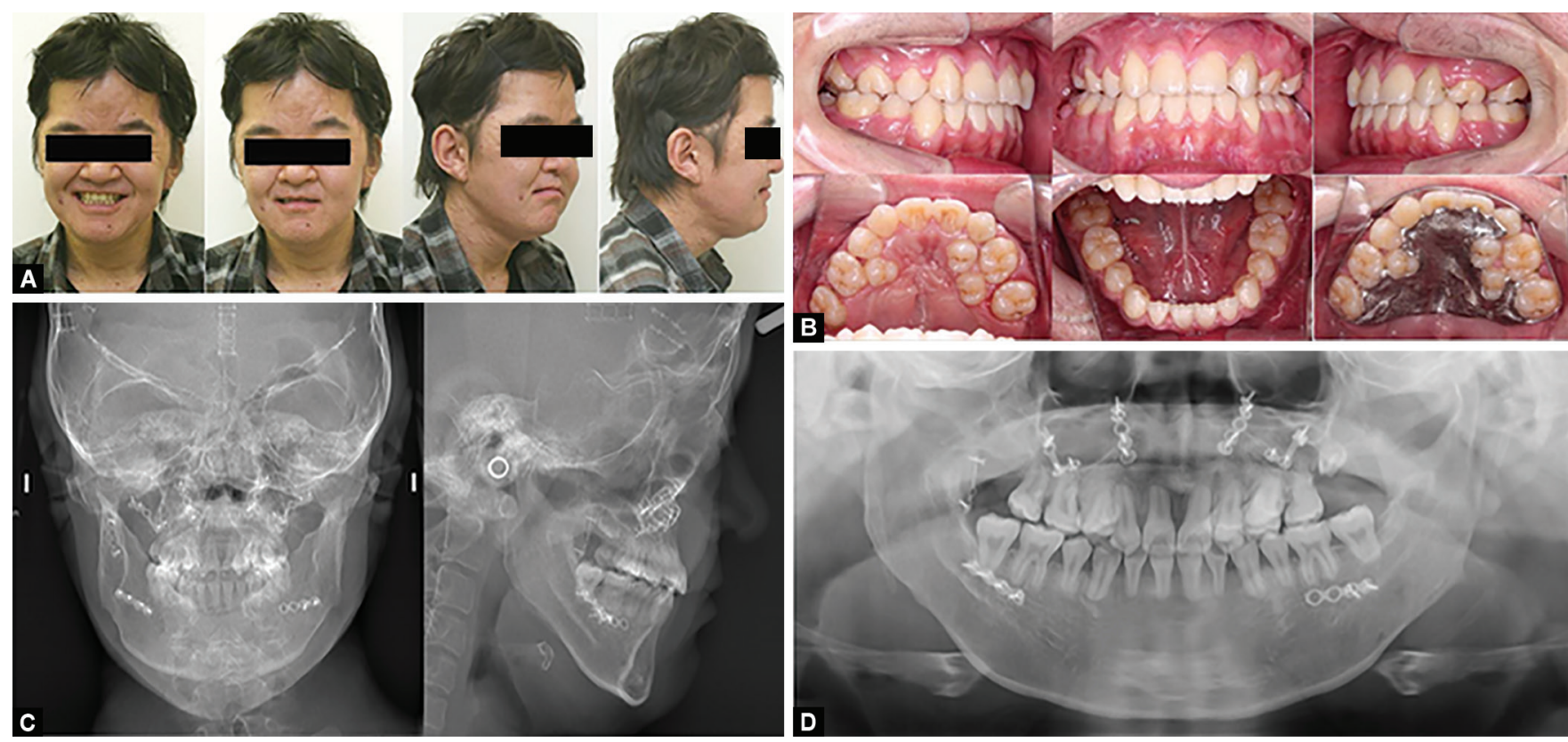

Figs 5A to D: Posttreatment: (A) Facial photographs; (B) Intraoral photographs; (C) Frontal and lateral cephalograms; (D) Panoramic radiograph

occlusion still remained (Figs $4 \mathrm{~A}$ and $\mathrm{B}$ ). Cephalometric analysis after distraction osteogenesis revealed a nasal advancement of $6.5 \mathrm{~mm}$ at the nasion, maxillary advancement of $7.0 \mathrm{~mm}$ at the anterior nasal spine, and $7.5 \mathrm{~mm}$ at the posterior nasal spine against the reference line, which was defined as a line perpendicular to the sella-nasion plane through the sella (Figs 2 and $4 C$, Table 1). The value of the ANB angle increased from $-11.6^{\circ}$ to $-5.3^{\circ}$ (Table 1). However, during the preoperative treatment period, the distracted maxilla moved $1.0 \mathrm{~mm}$ backward and the late growth of the mandible was observed, resulting in the ANB value decreasing to $-8.3^{\circ}$ at the age of 19 years and 9 months.
As a result of active treatment, a functional and acceptable occlusion with an adequate interincisal relationship was achieved (Figs $5 \mathrm{~A}$ and $\mathrm{B}$ ). The mandibular protrusion was dramatically improved. Overjet and overbite increased to 3.0 and $2.5 \mathrm{~mm}$, respectively. Panoramic radiograph revealed mild root resorption of the maxillary and mandibular anterior teeth (Fig. 5D). Cephalometric analysis revealed a maxillary advancement of $2.0 \mathrm{~mm}$ at the anterior nasal spine and a mandibular setback of $7.0 \mathrm{~mm}$ at the B-point to the aforementioned reference line (Figs 2 and 5C, Table 1). Since the mandible moved backward and upward, the value of the ANB angle improved from $-8.3^{\circ}$ to $-2.3^{\circ}$. As a result, his midfacial hypoplasia and the resultant protrusive mandible were corrected. 

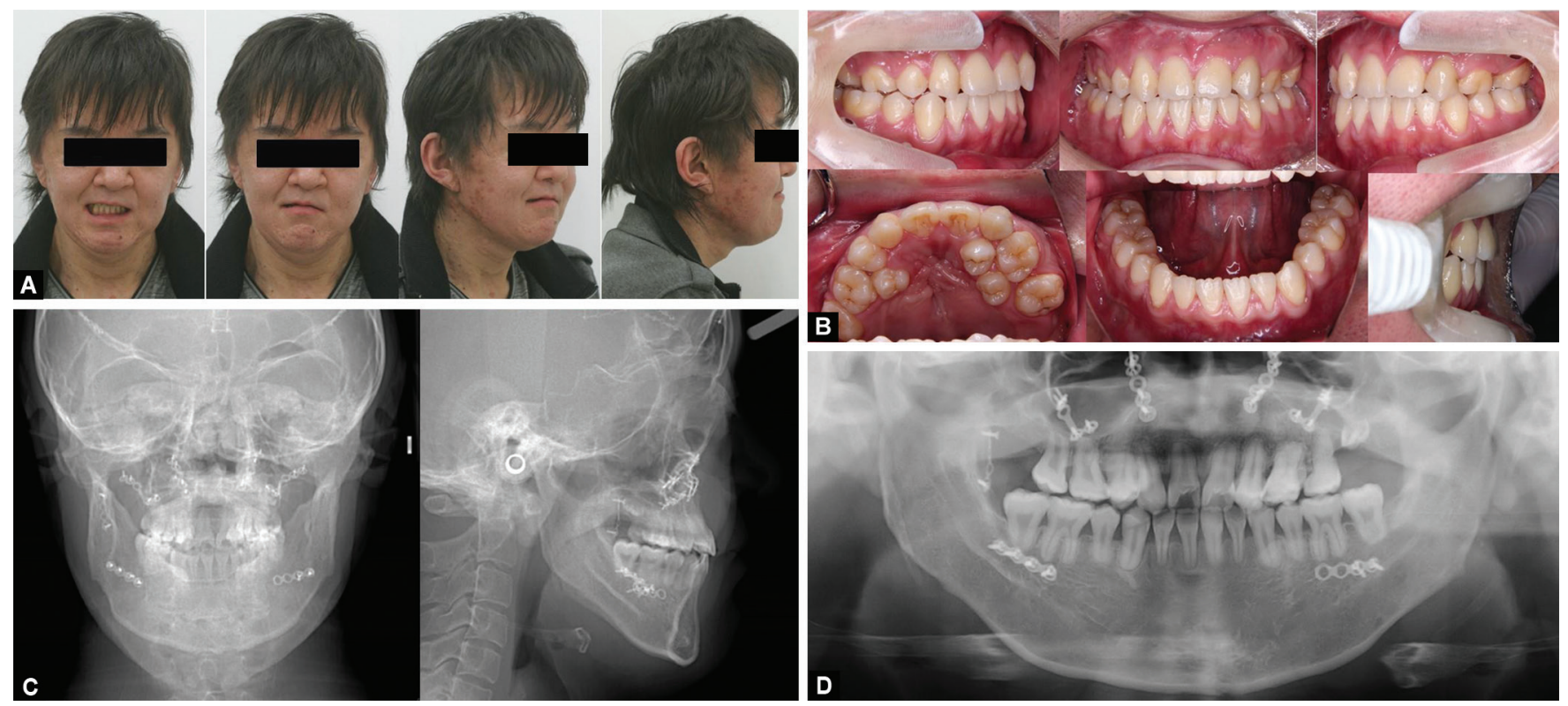

Figs 6A to D: After 2-year retention: (A) Facial photographs; (B) Intraoral photographs; (C) Frontal and lateral cephalograms; (D) Panoramic radiograph

Table 1: Cephalometric summary

\begin{tabular}{|c|c|c|c|c|c|c|c|c|}
\hline \multirow[b]{2}{*}{ Variable } & \multicolumn{2}{|c|}{$\begin{array}{l}\text { Japanese norm for } \\
\text { male adult }\end{array}$} & \multirow{2}{*}{$\begin{array}{c}\text { Pretreatment } \\
4 \text { years and } \\
5 \text { months }\end{array}$} & Predistraction & Postdistraction & \multirow{2}{*}{$\begin{array}{c}\text { Before two-jaw } \\
\text { surgery } \\
19 \text { years and } \\
9 \text { months }\end{array}$} & \multirow{2}{*}{$\begin{array}{c}\text { Posttreatment } \\
21 \text { years and } \\
9 \text { months }\end{array}$} & \multirow{2}{*}{$\begin{array}{c}\text { Postretention } \\
24 \text { years and } \\
11 \text { months }\end{array}$} \\
\hline & Mean & $S D$ & & $\begin{array}{l}15 \text { years and } \\
3 \text { months }\end{array}$ & $\begin{array}{l}16 \text { years and } \\
1 \text { months }\end{array}$ & & & \\
\hline \multicolumn{9}{|l|}{ Angular $\left({ }^{\circ}\right)$} \\
\hline SNA & 81.5 & 3.29 & 63 & 71.5 & 76.6 & 75.5 & 76.2 & 76 \\
\hline SNB & 78.2 & 4.02 & 74.2 & 83.1 & 81.9 & 83.8 & 78.5 & 78.3 \\
\hline ANB & 3.2 & 2.38 & -11.2 & -11.6 & -5.3 & -8.3 & -2.3 & -2.3 \\
\hline $\mathrm{Mp}-\mathrm{FH}$ & 28 & 6.08 & 32.2 & 25.2 & 23.8 & 21.2 & 27.8 & 28 \\
\hline Gonial angle & 120.9 & 6.51 & 135.4 & 129.8 & 129.6 & 127.5 & 126.6 & 126.6 \\
\hline U1-SN & 106 & 7.49 & 104 & 113.1 & 117.6 & 116.7 & 109.5 & 109.3 \\
\hline L1-MP & 95.2 & 6.18 & 78.5 & 84 & 92.8 & 83.7 & 78 & 78 \\
\hline Interincisal angle & 124.2 & 8.55 & 135.5 & 130.4 & 116.7 & 128.7 & 133.8 & 133.8 \\
\hline \multicolumn{9}{|l|}{ Linear (mm) } \\
\hline PTM-A/NF & 51.7 & 3.79 & 37.2 & 44.2 & 46.1 & 44.9 & 44.9 & 44.9 \\
\hline PTM-ANS/NF & 56.4 & 3.38 & 39.4 & 51.2 & 51.8 & 52 & 50.9 & 50.9 \\
\hline Go-Me & 76.6 & 4.37 & 54.5 & 68.7 & 66.5 & 68.9 & 70.6 & 70.6 \\
\hline Ar-Go & 53.2 & 5.7 & 45.3 & 49.7 & 49.8 & 55.7 & 44.7 & 44.7 \\
\hline
\end{tabular}

${ }^{*}$ Wada et al. ${ }^{15}$ SNA, sella-nasion-A-point angle; SNB, sella-nasion-B-point angle; ANB, A-point-nasion-B-point angle; Mp-FH, frankfort mandibular plane angle; U1-SN, angle of upper incisal axis and sella-nasion plane; L1-MP, angle of lower incisal axis and mandibular plane; PTM-A/NF, distance from pterygomaxillary fissure to A-point perpendicularly projected to nasal floor; PTM-ANS/NF, distance from pterygomaxillary fissure to anterior nasal spine perpendicularly projected to nasal floor; Go-Me, distance from gonion to menton; Ar-Go, distance from articulare to gonion

After a 2-year retention, at 3.0 and 7.6 years after two-jaw surgery and maxillary distraction osteogenesis, respectively, the maxilla and mandible were anteroposteriorly stable relative to the reference line. Facial profile was acceptable and a functional occlusion with a proper interincisal relationship (overjet, $3.0 \mathrm{~mm}$; overbite, $2.0 \mathrm{~mm}$ ) was well maintained (Figs 6A and $B$ ); however, the maxillary dental arch width was decreased by $0.5 \mathrm{~mm}$, resulting in the recurrence of the left posterior crossbite. Panoramic radiograph showed minimal changes in all teeth (Fig. 6D). Cephalometric analysis revealed a skeletal class I jaw-base relationship (ANB, $0.5^{\circ}$ ), and minimal changes in skeletal measurements were observed during the retention period (Figs 2 and 6C, Table 1).

\section{Discussion}

Due to the large variation of surgical procedures available and the phenotypical variability of the syndrome, there are a wide variety of treatment outcomes and protocols for the management of the craniomaxillofacial deformity in Apert syndrome. ${ }^{16}$ At present, 
although the midfacial advancement with distraction osteogenesis following Le Fort II or Le Fort III osteotomy has been utilized in the current treatment algorithm of Apert syndrome, the optimal timing of surgical maxillary advancement for midfacial hypoplasia has been controversial. Posnick et al. ${ }^{17}$ demonstrated that early midfacial advancement is suitable for patients with craniodysostosis with obstructive sleep apnea and/or severe exorbitism. Oberoi et al. ${ }^{18}$ recommended midfacial advancement using standard Le Fort III with bone grafts or distraction osteogenesis at the age of 9-12 years if the individual's cooperation allows. In addition, second-phase orthodontic treatment including orthognathic surgery after the end of the growth can be performed at the age of 12-21 years, if need be. ${ }^{18}$

The differences in the timing of midfacial advancement are discussed not only in terms of functional emergencies such as intraocular pressure and/or breathing, but also in terms of how the surgery affects the growth of the maxillary complex. ${ }^{18-20}$ When taking the individual growth and development into consideration to the maximum extent, the later the midfacial advancement is more beneficial, and the easier to predict the surgical outcome. Meanwhile, the early midfacial distraction is thought to have some advantages to reconstruct a large pharyngeal cavity, enlarge the airway, improve obstructive respiratory disorders, and to avoid tracheostomy. ${ }^{21}$ The decision of when to undergo surgery depends on a balance between the benefits of delaying surgery and the need to minimize any potential opposite effects on individual development from impaired ventilation, psychosocial disturbance, and severe exorbitism. ${ }^{22}$ The present patient, a classic case of Apert syndrome, underwent Le Fort III distraction osteogenesis at the age of 15 years and 4 months, followed by the two-jaw surgery at the age of 19 years and 10 months. Judging from previous studies, ${ }^{17,18}$ although the implementation time of the distraction osteogenesis was later, it would have been suitable for correcting the delayed mandibular growth that was unique to patients with craniodysostosis. $^{23}$

In the present case, Le Fort III distraction osteogenesis was chosen to improve midface hypoplasia of Apert syndrome. Current evidence demonstrated that both conventional Le Fort III osteotomy and Le Fort III distraction osteogenesis techniques enable us to move expectedly the midface forward in patients with syndromic midfacial hypoplasia and result in sufficient stability with a small amount of recurrence. ${ }^{24}$ In comparison with the conventional Le Fort III osteotomy, the Le Fort III distraction osteogenesis appears to complete a greater amount of midfacial advancement with a relatively small amount of relapse. The systematic review indicated that the amount of midfacial advancement was $8-12 \mathrm{~mm}$ in Le Fort III osteotomy and on average $9-16 \mathrm{~mm}$ in Le Fort III distraction osteogenesis. ${ }^{24}$ In addition, horizontal mild long-term follow-up study revealed that the maximal rate of relapse after Le Fort III osteotomy was on average 9.7\%, ${ }^{25,26}$ whereas after Le Fort III distraction osteogenesis, the horizontal long-term relapse rate was less than $10 \%$. Moreover, other studies demonstrated that Le Fort III osteodistraction enabled further advancement without any rate of relapse. ${ }^{27,28}$ In the present case, approximately $15 \%$ of maxillary relapse was observed 4.5 years after distraction, although the facemask was worn to retain the advanced midface. This is similar to the study of Meazzini et al. in which patients with early removal of the RED device revealed a relapse of 3-1.5 mm even though a Delaire mask was used. ${ }^{29}$ This implies that long-term rigid retention including intraoral fixation should be considered to avoid sufficient stability after midfacial advancement with distraction osteogenesis.
It is generally essential to retain the vertical height of the midface during Le Fort III distraction osteogenesis as much as possible, because a downward movement of the maxillofacial complex accelerates the clockwise rotation of the mandible, resulting in the onset and impairment of the anterior open bite. In our patient, the mandible slightly rotated clockwise; however, it contributed to improving his deep overbite.

\section{Conclusion}

We report the long-term follow-up and surgical orthodontic treatment of a patient with Apert syndrome with midfacial hypoplasia and Le Fort III distraction osteogenesis before multibracket treatment and with two-jaw surgery including Le Fort I osteotomy and mandibular sagittal split ramus osteotomy after preoperative treatment. As a result of the two-stage operation, the facial profile was dramatically changed to the balanced profile, and a functional and acceptable occlusion with an ideal interincisal relationship was achieved. The functional occlusion with a balanced profile was well maintained throughout the 2-year retention period, although the maxillary dental arch width decreased, resulting in the recurrence of the left posterior crossbite. In conclusion, our results indicate the necessity of a long-term follow-up in patients with craniosynostosis.

\section{Consent for Publication}

Written informed consent was obtained from the patient for publication of this case report and any accompanying images.

\section{Authors' Contributions}

Shinya Horiuchi, Hiroko Sato, and Aki Ichihara contributed to performing the orthodontic treatment. Akihiko Iwasa, Hirofumi Tenshin, and Masahiro Hiasa contributed to analyzing the cephalometric data. Ichiro Hashimoto contributed to performing orthognathic surgery. Shinya Horiuchi and Eiji Tanaka contributed to the planning of orthodontic treatment and writing the manuscript. All authors read and approved the final manuscript.

\section{References}

1. Cohen MM, Kreiborg S. Skeletal abnormalities in the Apert syndrome. Am J Med Genet 1993;47(5):624-632. DOI: 10.1002/ajmg.1320470509.

2. Park WJ, Theda C, Maestri NE, et al. Analysis of phenotypic features and FGFR2 mutations in Apert syndrome. Am J Hum Genet 1995;57(2):321-328. PMID: 7668257.

3. Cohen MM, Kreiborg S. A clinical study of the craniofacial features in Apert syndrome. Int J Oral Maxillofac Surg 1996;25(1):45-53. DOI: 10.1016/s0901-5027(96)80011-7.

4. Ciurea AV, Toader C. Genetics of craniosynostosis: review of the literature. J Med Life 2009;2(1):5-17. PMID: 20108486.

5. Ferraro NF. Dental, orthodontic, and oral/maxillofacial evaluation and treatment in Apert syndrome. Clin Plast Surg 1991;18(2):291-307. PMID: 2065490.

6. Cohen SR, Rutrick RE, Burstein FD. Distraction osteogenesis of the human craniofacial skeleton: initial experience with new distraction system. J Craniofac Surg 1995;6(5):368-374. DOI: 10.1097/00001665199509000-00007.

7. Polley JW, Figueroa AA. Management of severe maxillary deficiency in childhood and adolescence through distraction osteogenesis with an external, adjustable, rigid distraction device. J Craniofac Surg 1997;8(3):181-185; discussion 186. DOI: 10.1097/00001665-19970500000008.

8. Krimmel M, Cornelius $C P$, Roser $M$, et al. External distraction of the maxilla in patients with craniofacial dysplasia. J Craniofac Surg 2001;12(5):458-463. DOI: 10.1097/00001665-200109000-00011. 
9. Kuroda S, Araki Y, Oya S, et al. Maxillary distraction osteogenesis to treat maxillary hypoplasia: comparison of an internal and an external system. Am J Orthod Dentofacial Orthop 2005;127(4):493-498. DOI: 10.1016/j.ajodo.2004.08.014.

10. Figueroa AA, Polley JW. Management of severe cleft maxillary deficiency with distraction osteogenesis: procedure and results. Am J Orthod Dentofacial Orthop 1999;115(1):1-12. DOI: 10.1016/S08895406(99)70310-0.

11. Kuroda S, Watanabe K, Ishimoto K, et al. Long-term stability of Le Fort III distraction osteogenesis with a rigid external distraction device in a patient with Crouzon syndrome. Am J Orthod Dentofacial Orthop 2011;140(4):550-561. DOI: 10.1016/j.ajodo.2009.12.038.

12. Matsumoto $K$, Urano $Y$, Kubo Y, et al. Mutation of the fibroblast growth factor receptor 2 gene in Japanese patients with Apert syndrome. Plast Reconstr Surg 1998;101(2):307-311. DOI: 10.1097/00006534199802000-00007.

13. Tanimoto $Y$, Yokozeki $M$, Hiura $K$, et al. A soluble form of fibroblast growth factor receptor 2 (FGFR2) with S252W mutation acts as an efficient inhibitor for the enhanced osteoblastic differentiation caused by FGFR2 activation in Apert syndrome. J Biol Chem 2004;279(44):45926-45934. DOI: 10.1074/jbc.M404824200.

14. Matsumoto K, Nakanishi H, Koizumi Y, et al. Correction of a deformed thumb by distraction of the phalanx. Scand J Plast Reconstr Surg Hand Surg 2002;36(6):368-372. DOI: 10.1080/028443102321096375.

15. Wada K, Matsushita K, Shimazaki S, et al. An evaluation of a new case analysis of a lateral cephalometric roentgenogram. J Kanazawa Med Univ 1981;6:60-70.

16. Posnik JC, Ruiz RL, Tiwana PS. Craniofacial dysostosis syndromes: stages of reconstruction. Oral Maxillofacial Surg Clin N Am 2004;16(4): 475-491. DOI: 10.1016/j.coms.2004.08.004. PMID: 18088749.

17. Posnick JC, Armstrong D, Bite U. Crouzon and Apert syndromes: Intracranial volume measurements before and after cranio-orbital reshaping in childhood. Plast Reconstr Surg 1995;96:539-548. PMID: 7638278

18. Oberoi S, Hoffman WY, Vargervik K. Craniofacial team management in Apert syndrome. Am J Orthod Dentofacial Orthop 2012;141(4 Suppl):S82-S87. DOI: 10.1016/j.ajodo.2012.01.003.

19. Figueroa AA, Polley JW, Friede $H$, et al. Long-term skeletal stability after maxillary advancement with distraction osteogenesis using a rigid external distraction device in cleft maxillary deformities. Plast
Reconstr Surg 2004;114(6):1382-1392; discussion 1393-1394. DOI: 10.1097/01.prs.0000138593.89303.1b.

20. Satoh K, Mitsukawa N, Hosaka Y. Dual midfacial distraction osteogenesis: Le Fort III minus I and Le Fort I for syndromic craniosynostosis. Plast Reconstr Surg 2003;111(3):1019-1028. DOI: 10.1097/01.PRS.0000047440.06788.72.

21. Mitsukawa N, Kaneko T, Saiga A, et al. Early midfacial distraction for syndromic craniosynostotic patients with obstructive sleep apnoea. J Plast Reconstr Aesthet Surg 2013;66(9):1206-1211. DOI: 10.1016/ j.bjps.2013.04.061.

22. Breik O, Mahindu A, Moore MH, et al. Apert syndrome: Surgical outcomes and perspectives. J Craniomaxillofac Surg 2016;44(9): 1238-1245. doi: 10.1016/j.jcms.2016.06.001.

23. Susami T, Fukawa T, Miyazaki $H$, et al. A survey of orthodontic treatment in team care for patients with syndromic craniosynostosis in Japan. Cleft Palate Craniofac J 2018;55(4):479-486. DOI: 10.1177/1055665617747703.

24. Saltaji H, Altalibi M, Major MP, et al. Le Fort III distraction osteogenesis versus conventional Le Fort III osteotomy in correction of syndromic midfacial hypoplasia: a systematic review. J Oral Maxillofac Surg 2014;72(5):959-972. DOI: 10.1016/j.joms.2013.09.039.

25. Shetye PR, Boutros S, Grayson BH, et al. Midterm follow-up of midface distraction for syndromic craniosynostosis: a clinical and cephalometric study. Plast Reconstr Surg 2007;120(6):1621-1632. DOI: 10.1097/01.prs.0000267422.37907.6f.

26. Lee DW, Ham KW, Kwon SM, et al. Dual midfacial distraction osteogenesis for Crouzon syndrome: long-term follow-up study for relapse and growth. J Oral Maxillofac Surg 2012;70(3): e242e251. DOI: 10.1016/j.joms.2011.11.010.

27. Shetye PR, Davidson EH, Sorkin M, et al. Evaluation of three surgical techniques for advancement of the midface in growing children with syndromic craniosynostosis. Plast Reconstr Surg 2010;126(3): 2061-2070. DOI: 10.1097/PRS.0b013e3181e6051e.

28. Iannetti G, Ramieri V, Pagnoni M, et al. Le Fort III external midface distraction: surgical outcomes and skeletal stability. J Craniofac Surg 2012;23(3):896-900. DOI: 10.1097/SCS.0b013e31824e2549.

29. Meazzini MC, Allevia F, Mazzoleni F, et al. Long-term follow-up of syndromic craniosynostosis after Le Fort III halo distraction: a cephalometric and CT evaluation. J Plast Reconstr Aesthet Surg 2012;65(4):464-472. DOI: 10.1016/j.bjps.2011.09.048. 